\title{
CORONELISMO E CONTEXTOS HISTÓRICOS ${ }^{1}$
}

Isnara Pereira lvo ${ }^{2}$

RESUMO:

O artigo analisa os principais estudos sobre o coronelismo mostrando como os historiadores têm definido a incursão do poder privado nas instituições públicas. Também discute as interpretações desse fenômeno no interior da Bahia, especificamente, as pesquisas sobre a Região Cacaueira, a Chapada Diamantina, o BaixoMédio São Francisco e o Planalto de Conquista.

UNITERMOS: coronclismo, poder público, poder privado.

Mandonismo, coronelismo, privatismo, familismo, clientelismo e muitos outros conceitos são utilizados para designar a interferência do poder privado no domínio público. Muitas vezes utilizados como sinônimos das manifestaçôes do poder privado no Brasil, tais conceitos são constantemente revisitados por historiadores, sociólogos e cientistas políticos, que reiteram a atualidade do tema e a necessidade de analisar as especificidades regionais não só no sentido de recuperar as histórias locais, mas também de exercer um "continuar" da história esquecida nas grandes sínteses.

Esses conceitos, referentes a um mesmo fenômeno, têm levado alguns estudiosos a uma visão bipolarizada da estrutura política e administrava do Brasil. De um lado, estão os autores

\footnotetext{
'Análise desenvolvida em dissertação de mestrado da autora. Ver Ivo (1998).

2Irofessora Assistente do Departamento de História da Universidade Estadual do Sudoeste da Bahia/UESB. Mestre em História pela UFMC.
} 
que atribuem grande importância ao poder local como microesfera da estrutura político-administrativa do Estado; de outro, tem-se uma abordagem clássica do poder central visto em seu caráter progressivamente forte e centralizador. No primeiro grupo, inserem-se os trabalhos de Maria Isaura Pereira de Queiroz (QUeIroZ, 1976a) e Victor Nunes Leal (LEAL, 1975); no segundo, o clássico estudo de Raimundo Faoro (FAORO, 1996).

Dentre os autores que atribuem grande importância ao localismo na política nacional está Pereira de Queiroz, autora que analisa a influência do mandonismo local, o qual, na sua perspectiva, sobrepõe-se ao poder central nas três fases da vida política nacional. Assim,

paralelamente ao mandonismo que se afirma em todas as ocasiões como o poder mais forte, veio-se desenvolvendo também um poder central. Este não é senão uma tentativa durante a Colônia. Durante o Império confunde-se com o mandonismo local; o amálgama localismo-centralismo [...]. Finalmente, durante a Primeira Repúllica, o poder central principia a se desvencilhar do coronelismoe a constituir uma força independente com a qual é preciso contar; chega mesmo a um equililibrio de forç̧as, e governo central e mandōes políticos tratam-se de potência para a potência (QUEIROZ, 1976a, p. 33) 3.

Conclui Pereira de Queiroz que a forte influência do mandonismo local, mesmo paralela ao processo de centralização do Estado, é resultante da permanência de uma estrutura social baseada no latifúndio e na escravidão:

De Portugal viera para o Brasil o tipo de família patriarcal [...] e que encontrou no Brasil, para revigorar e perdurar, as seguintes condiç̧ôes:

\footnotetext{
Note-se que a autora parece confundir os dois conceitos: coronelismo e mandonismo lecil.
} 
latifúndio e escravidão, que tornavam o chefe de família senhor solve grande extensão de terra mal policiada e sobre grande quantidade de gente (QUEIROZ, 1976a, p. 44).

No Município estavam localizados os interesses imediatos dos latifundiários, senhores de gente e de coisas. Tornados proprietários dos destinos locais e também pessoais, os latifundiários comandavam a política de acordo com seus interesses. Sua ação política não se limitava às fronteiras de seu Município de influência, ao contrário, a política local, que em tomo deles acontecia, determinava a composição das Câmaras Provinciais, e por sua vez, do gahinete. Assim, segundo Pereira de Queiroz, durante o Império, em lugar da centralização do poder nas mãos do Imperador, o que havia era a sua fragmentação nas mãos dos proprietários agrícolas.

As modificações no âmbito político e administrativo, advindas com a implantação do regime republicano, na interpretação da autora, não alteraram o centro da política dos mandóes locais, agora configurado na pessoa do coronel. O Município permaneceu como instrumento privilegiado dos chefes locais. O coronelismo nada mais é do que a forma assumida pelo mandonismo local, a partir da Proclamação da República, apesar de a denominação de coronel ter aparecido ainda na segunda metade do Império (QUEIROZ, 1976b, p. 172). O fenômeno, que durante o Império se mantivera à sombra, veio à tona na República, demonstrando um pacto tácito: "entre o Presidente ou o chefe estadual e a massa votante se interpunham os coronéis" (QUEIROZ, 1976a, p. 117-118).

A autora parece perceber nesse pacto uma diminuição do poder dos mandóes locais, ao afirmar que o"chefe municipal tinha de se acomodar com dois poderes diferentes: o governo do Estado e o governo da República" (QUEIROZ, 1976a, p. 125). O que o novo jogo político demonstra, na realidade, é uma função especial 
do papel dos chefes locais na política, agora institucionalizada, não só local e regionalmente, mas também em nível nacional.

O poder econômico dos coronéis é relativizado pela autora, ao concluir que, durante a Primeira República, a simples propriedade de grandes quantidades de terra não era fator de riqueza; isto só se verificava quando havia por parte do proprietário capital suficiente para sua exploração. O comércio foi o instrumento eleito para se fazerem fortunas, e sua conservação e ampliação se davam por heranças e casamentos.

No que se refere à dominação política dos coronéis, Pereira de Queiroz explica sua natureza na determinação social representada pelos grupos de parentela. Esses grupos, diferenciados, dos "clãs" ou das "familias extensas", constituíam-se em núcleo extenso de indivíduos unidos por parentesco de sangue e eram formados por várias famílias nucleares, economicamente independentes.

Observa a autora que os laços de solidariedade não levam intrinsecamente à harmonia e que as disputas entre esses grupos, lutas de família, podem, inclusive, reforçar a solidariedade interna: "a quebra da solidariedade do conjunto maior agia como um fator de reforço poderoso da solidariedade interna dos conjuntos menores, adversários entre si" (QUEIROZ, 1976a, p. 183).

Com base nesses fundamentos, e utilizando a tipologia de Jean Blondel (BLONDEL, 1957), Pereira de Queiroz interpreta a força eleitoral dos coronéis a partir de três tipos de estrutura coronelística: o mando direto, quando o coronel controla sua parentela pessoalmente e com auxílio de cabos eleitorais; o mando indireto, quando um coronel lidera outros coronéis de menor influência e o mando colegial, quando coronéis dominam zonas diferentes, e detêm poderes equiparáveis.

É importante notar que a autora, ao explicar os fundamentos 
e constituição do fenômeno do coronelismo, o faz a partir da análise dos aspectos mais internos da sociedade local, ao passo que, ao tentar explicar a extinção do mesmo fenômeno, busca aspectos extrínsecos à estrutura de seu desenvolvimento, ou seja, explica o desaparecimento do coronelismo pela crescimento demográfico, pela industrialização e pela urbanização.

Análise diversa sobre o fenômeno coronelismo foi desenvolvida em Coronelismo, enxada e voto por Victor Nunes Leal (LEAL, 1975) que concebe o mandonismo, assim como o filhotismo, of falseamento do voto e a desorganização dos serviços públicos locais como características da política tradicional brasileira, que são, na realidade, características secundárias do "sistema coronelista". Nunes Leal não desenvolve uma análise do mandonismo local no decorrer da história política nacional, apesar de considerá-lo existente durante a Colônia e o Império. Sua atenção está voltada, única e exclusivamente, para um fenômeno próprio da Primeira República, o coronelismo como sistema político historicamente definido e localizado:

O yue procurei examinar foi o sistema. O coronel entrou na análise por ser parte do sistema, mas o que mais me preocupava era o sistema, a estrutura e a maneira pelas cutais as relações de poder se desenvolviam na Primeira República, a partir do Município (LEAL, 1980, p. 11-14).

Ocoronelismo resume-se num compromisso resultante da superposição de uma estrutura agrária arcaica a um sistema político modernizado. Os compromissos são recíprocos e envolvem o Governador do Estado, o Presidente da República e o coronel, o principal eixo do sistema de reciprocidade.

Assim como Pereira de Queiroz, o autor considera o enfraquecimento paulatino da influência social e política dos chefes locais nesse período, situação que os condiciona ao 
compromisso com os chefes hierarcuicamente superiores: "um compromisso, uma troca de proveitos entre o poder público, progressivamente fortalecido, e a decadente influência social dos chefes locais, notadamente os senhores de terras" (LEAL, 1975, p. 20). E, reverso do espelho desse sistema de compromisso é o reconhecimento mútuo pelo chefe local, o coronel, e o governo estadual da importância política de cada um.

O autor compreende que o coronelismo é também resultante da falta de autonomia dos Municípios que, de um lado, enfraquece o poder público municipal permitindo a hipertrofia do poder privado dos donos de terras; e de outro, permite a subordinação do coronel ao governo estadual, posto que a política discricionária dos coronéis "não poderia assumir as proporções habituais sem o apoio da situação política estadual" (LEAL, 1975, p. 44). Assim, a falta de autonomia municipal proporciona aos chefes locais uma autonomia extralegal que é legitimada pelo governo estadual.

Com esse mecanismo, o governo estadual subordinou os Municípios aos desmandos dos coronéis, outorgando-lhes o "direito" à nomeação das autoridades municipais e fazendo "vistas grossas" às violências e arbitrariedades cometidas nas localidades. Por outro lado, o coronel também assume a função de legitimador do governo estadual e federal, uma vez que possui a força eleitoral que se concretiza através de sua capacidade de negociar ou trocar favores com o governo do Estado. Vale lembrar que, para o autor, a força eleitoral e a propriedade fundiária são os elementos mantenedores do coronelismo. Apontados como fatores para a sua superação, a modificação na estrutura agrária do país, " processo de industrialização, o desenvolvimento dos meios de comunicação, o aperfeiçoamento do processo eleitoral e a vitalização do Município pela Constituição de 1946 (LEAL, 1975, p. 256-257). 
Diferentemente de Nunes Leal, Raimundo Faoro (FAORO, 1996) retorna ao processo de formação do Estado brasileiro para justificar o surgimento do coronelismo. Conclui o autor que a Proclamação da República com o novo Estado, em busca de legitimação política e estahilidade social, consolidou a nova ordem com a "política dos governadores", instituída por Campos Sales (1898-1902), alicerçada no poder dos coronéis:

a supremacia tuteladora do poder público, agora secionado nos principados e ducados estaduais, continuou a operar, num molde próximo an regime colonial, no qual o particular exercia, por investidura ou reconhecimento oficial, funçñes públicas (FAORO, 1996, p. 631).

O coronel, assin, exercia uma função política alheio ao discernimento entre o poder estatal e os fins privados. Na realidade, exercia o ofício de complementar a administração púhlica no âmbito local através de grupos políticos não monolíticos em função das dissenções oriundas das disputas entre famílias locais. Nesse sentido,

o fenômeno coronelista não é novo. Nova será a sua coloração) estadualista e sua emancipação no agrarismo republicano, mais liberto das peias e das dependências econômicas do patrimonialismo central do Império (FAORO, 1996, p. 621).

O poder do coronel origina-se de um "pacto não escrito" no yual the é reconhecido e outorgado um poder justificado pela força eleitoral que possui e que será acentuado na passagem do regime imperial para o republicano que, desejoso de legitimação, "atrelará os chefes políticos municipais ao governo estadual, com a atrofia dos núcleos locais", o que em tese significava, "atrelar 
os monarquistas aos freios republicanos, realizar eleições sobo domínio das situações estaduais" (FAORO, 1996, p. 623).

Ocorre que, apesar do federalismo, o controle central de todo esse processo pertence ao poder federal; é ele, em última instância, o dono do poder. O Governador subordina as eleições municipais, cujo aliciador de votos é o coronel, mas a correlação de forças entre este e o governo estadual é, segundo o autor, inversamente proporcional: "sempre que o poder estadual se eleva e se fortalece decai o poder municipal" (FAORO, 1996, p. 626). Mas, a força decisória será sempre a do governo central que, na medida em que comanda a política econômica e financeira, restringe o poder coronelista que tende a se tornar desnecessário, e consequentemente, torna também desnecessárias as relações entre os sistemas estadual e federal.

Essas teses "centralistas" e "localistas" demonstram um paradoxo apenas aparente. O fortalecimento do poder local eo progressivo processo de centralização do Estado não são incompatíveis; na realidade, são complementares, uma vez que a formação do Estado e, principalmente, a crescente centralização política e administrativa tiveram nos chefes políticos locais sua base de apoio, os quais, em troca, retribuíam o paternalismo do poder central. Através das eleições para o legislativo estadual e federal, o poder local, com seus líderes, referendou a política centralista sem prescindir de sua influência em nível local.

Estudo inovador foi desenvolvido por Maria de Lourdes Janotti. De acordo com sua interpretação, o coronelismo tem uma estrutura "bastante plástica, adaptando-se a sucessivos momentos históricos" (JANOTTI, 1981, p. 80). Assim, para ela, o coronelismo nada mais é do que uma vertente do mandonismo sempre presente na Colônia, no Império e na República.

Discussão seminal em seu trabalho refere-se ao fim do coronelismo. A plasticidade de sua política o permite sobreviver 
mesmo após a Revolução de 30, com suas modificações na estrutura e nas relaçóes de poder. Apesar de admitir que o coronelismo desaparece nas áreas de maior concentração urbana, a autora percehe que na nova estrutura dos grandes centros

há certos traços de paralelismo entre a figura do coronel e a dos chefes populistas; anbos utilizam na concuista do eleitorado o empreguismo, o favoritismo, a barganha eleitoral, o compadrio e a violência (JANOTTI, 1981, p. 82).

Alguns traços comuns entre os líderes populistas e o coronel são também percebidos por João Gualberto Vasconcelos que vê naqueles e também no tecnocrata, atores políticos com raízes no imaginário político e social do coronel:

mesmo que o populismo seja um fenômeno político da era Vargas, não há risco em afirmar que ele começou a existir na República Velha, e afirmar também, sem riscos de errar, cue sua ação política sempre foi muito próxima da do coronel (VASCONCELOS, 1995, p. 95).

Outros estudos sobre o mandonismo ou coronelismo desenvolvem abordagens locais em nível das realidades estaduais sem, contudo, fugir das análises generalizantes. Alguns deles constróem seus próprios referenciais teóricos para a ahordagem do tema, a exemplo de Bursztyn (BURSZTYN, 1985) an analisar planejamento e clientelismo no Nordeste e Eul Soo-Pang (PANG, 1979), em seu estudo cobre o coronelismo e as oligarquias baianas. No entanto, para esse momento, serão privilegiados os trabalhos referentes ao Estado da Bahia, no sentido de diferenciar as manifestações de mandonismo no interior do Estado demonstrando as especificidades dos contextos históricos em que estão inseridos. 
Pang elege o período de 1889 a 1930 para estudar o coronelismo e as oligarquias na Bahia. Construindo um modelo de interpretação próprio, justifica sua opção pela Primeira República por considerá-la um momento de transição, não só em nível social e econômico, mas também em nível do comportamento político das classes dominantes. Usando Tocqueville, que observou uma crise de legitimidade e de eficiência no governo no período de transição da monarquia aristocrática para a república democrática, Pang identifica uma situação similar no Brasil da Primeira República, quando "os líderes informais, personalistas, como os coronéis brasileiros, são freqüentemente preferidos en lugar da autoridade formal e distante do Estado" (PANG, 1979, p. 9). Dessa forma, o coronelismo proporcionou a manutenção das oligarquias tradicionais no poder.

Com essa característica própria dos momentos de transição, a formação política brasileira, com seu caráter patrimonialista na concepção weberiana, construirá os alicerces do coronelismo com todas as suas nuanças. Dessa forma, o coronelismo surgiu e se desenvolveu em um período de crise e instabilidade. Para Pang, o coronelismo é um

exercício de poder monopolizante por um coronel cuja legitimidade e aceitação se baseiam em seu status, de senhor absoluto, e nele fortalecem, como elemento dominante nas instituições sociais, economicas e políticas (PANG, 1979, p. 20).

$O$ autor não considera como base do coronelismo a propriedade fundiária; para ele, as mudanças ocorridas no Brasil, entre 1850 e 1950, alteraram a estrutura de classe de uma sociedade predominantemente agrária. A ausência de um Estado forte e centralizado nesse período favoreceu o desenvolvimento do coronelismo. 
A periodização que Eul-Soo Pang faz do fenômeno tem seu início no século XVIII e o apogeu, na Bahia, nos anos 20 e no período de 1933-37 com Juracy Magalhães. Em seu estudo do processo político-partidário, diferencia várias facções oligárquicas que disputaram o poder estadual na Bahia, caracterizando os grupos de acordo com sua composição:

familiocrático, dominado por uma família extensa; tribal, chefiado por um "padrinho" influente que acata autonomia dos membros assuciados; colegiado, organizado através de partidos e com rodízio de lideranças; e personalista, unido pela carisma do líder (PANG, 1979, p.39-45).

Para ele, foi o tipo familiocrático que caracterizou os coronéis da Bahia.

Dos autores analisados, além de João Gualberto de Vasconcelos, Pang é o cue mais se preocupa em analisar a violência institucionalizada pelos grupos privados, concluindo que ela remonta ao clã brasileiro, à família extensa, que, proprietária de exércitos particulares e ocupante de cargos públicos lutava pelos mais diversos motivos, "por questões de terras, de águas, por disputas eleitorais e freçüentemente por crimes passionais" (PANG, 1979, p. 24).

Pang justifica a legitimação da violência desses grupos, em primeiro lugar, pelo exercício de cargos públicos por eles obtidos e em segundo, pelo fato de os exércitos colonial e imperial serem relativamente pequenos e concentrarem-se principalmente nas cidades costeiras, ao passo que

em muitos Municípios do interior, o Estado não possuía meios de fazer cumprir a lei e o funcionamento da justiça; esses vazios foram rapidamente preenchidos pela justiça de Salomão, do patriarca e de seus exércitos particulares (PANG, 1979, p. 25). 
Um outro estudo sobre a Bahia, especificamente sobre a região cacaueira, foi desenvolvido por Gustavo Falcón (FALCÓN, 1995), jovem marxista, como se autodenomina. Sua análise marxista percebe o coronel como agente do avanço do capitalismo na região e membro de uma "burguesia cacaueira" de produtores e exportadores. A propriedade fundiária, produtora de cacau, aliada ao capital, foi, na região, a condição básica de exercício do mando coronelista que, apesar dessas especificidades regionais, guardou semelhança com o mandonismo local prevalecente na República velha em todo o país. Por não possuírem prestígio junto ao Estado, os chefes locais da região cacaueira adotaram uma postura mais legalista. A utilização de bacharéis em direito pelos proprietários rurais, em Ilhéus, teve um aspecto bastante relevante:

detendo o poder de fato, os coronéis buscavam de toda maneira amparar-se na forma da lei, orientando seus aliados bacharéis para "serviços" de toda ordem no sentido de se beneficiarem das contingências e desamparo dos pequenos lavradores (FALCÓN, 1995, p.94).

Informa o autor que, no período, o número de advogados na região superou até mesmo o de médicos.

A questão central desenvolvida pelo autor refere-se ao fato de a burguesia cacaueira de llhéus, apesar de ser a classe mais rica do Estado, não conseguir impor-se politicamente como liderança em nível regional. Conclui que, diferentemente da região da Chapada Diamantina e do São Francisco, a zona cacaueira não conseguiu, também, produzir formas de mando personificadas num único coronel. O dinamismo econômico da região e os conseqüentes conflitos abertos pela posse da terra permitiram uma sucessão de chefes regionais no poder, não tendo a região produzido nomes que se destacassem na história política do Estado, tais como Horácio de Matos e Franklin Lins de Albuquerque. 
Ocorre, no entanto, que o autor utiliza o conceito de mandonismo e coronelismo como similares. Elegendo a Primeira República como corte temporal, afirma que o "mandonismo atingiu seu apogeu durante a República Velha" (FALCÓN, 1995, p. 13) e, mais adiante, afirma que esse momento se constitui num "período épico do coronelismo" (FALCÓN, 1995, p. 14). Mesmo chamando a atenção para as especificidades regionais do seu "estudo de caso", não diferencia os conceitos que têm levado os historiadores a incorrer no erro de adaptações de paradigmas a realidades históricas locais e bastantes diversificadas, como é o caso do próprio mandonismo na região cacaueira por ele estudado.

Entre os demais trabalhos sobre o mandonismo no interior do Estado da Bahia, estão duas dissertações do mestrado em Ciências Sociais da Universidade Federal da Bahia: a de Dora Leal Rosa, intitulado O mandonismo local na Chapada Diamantina (ROSA, 1973, p.93), e a de Maria Alha Guedes Machado Mello, História Política do Baixo-Médio São Francisco: um estudo de caso do coronelismo (MELLO, 1989, p. 139). Acrescente-se a esses estudos a contribuição do jornalista Walfrido Moraes com o seu Jagunços e heróis (MORAES, 1973), brilhante análise sobre a família e a liderança de Horácio de Matos na região das Lavras Diamantinas.

$\mathrm{Na}$ Chapada Diamantina, o mandonismo local foi estudado por Leal Rosa, a partir da análise da combinação dos seguintes fatores: família extensa do tipo patriarcal, grande propriedade e isolamento. O estudo teve como objeto a análise da trajetória política do coronel Horácio de Matos e dos membros do seu grupo familiar, senhores proprietários de terras e de garimpos na Chapada durante o período de 1912 a 1930. A autora, a partir do conceito de coronelismo de Victor Nunes Leal, analisou os mecanismos de posse da terra; as famílias, com seus líderes, os 
coronéis; as relações estabelecidas internamente nos grupos de parentela e dessa com a ordem pública, e conseqüentemente, as disputas pelo controle do poder na região.

Analisando as relações entre o coronel e a ordem pública, demonstra como o sistema coronelista configura-se numa via de mão dupla. Em alguns momentos, os chefes locais, controlados pelo governo federal, são submetidos e condicionados aos interesses políticos regionais; em outros momentos, é o governo federal que se submete ao poder local, sendo obrigado a parlamentar com os chefes locais no sentido mesmo de garantir sua autoridade diante da força armada dos mandões locais. O exemplo maior foi a Revolução Sertaneja, liderada por Horácio de Matos, resultante da política de oposição implementada contra o sucessor ao governo do Estado, José Joaquim Seabra.

A campanha pela sucessão do governador Antônio Muniz Ferrão de Aragão (1916-1920), caminhava para que o seu antecessor, José Joacpuim Seabra (1912-1916), voltasse ao governo. Horácio de Matos, conseguindo o apoio dos coronéis locais da região das Lavras, decidiu pelo apoio ao grupo político de oposição liderado por Rui Barbosa, no qual figuravam os mais ilustres políticos do Estado. Com a realização do pleito, tanto a oposição como o governo diziam-se vitoriosos. A oposição, que tinha como candidato Paulo Martins Fontes, denominou o pleito de "Orgia de Fraude e Sangue" (MORAES, 1973, p. 82).

A partir desse momento, Horácio de Matos liderou a Revolução Sertaneja, sitiando e invadindo as cidades da região rumo à capital do Estado, do que resultou a ação intervencionista do governo federal em 23 de fevereiro de 1920, e com o envio de tropas do exército ao Estado.

Ocorre que o governo federal, através da intervenção no Estado, não conseguiu alcançar seus objetivos iniciais que eram 
os de restahelecer a ordem e a tranqüilidade públicas no Estado. Admitindo sua própria falta de autoridade diante dos coronéis da Chapada Diamantina, sob a liderança de Horácio de Matos, o governo assumiu uma proposta de armistício com os chefes locais, assinando dessa forma, também, a sua capitulação diante das forças coronelísticas locais. O tratado de paz entre o governo e os coronéis da região foi denominado "Convênio de Lençóis", acordo no qual ficou reconhecido e garantido o domínio político de Horácio de Matos na região.

Na outra dissertação citada, Machado Mello estudou o coronelismo durante as quatro primeiras décadas da República, na região baiana do Baixo-Médio São Francisco, e limitou sua pesquisa aos Municípios de Pilão Arcado, Sento Sé, Remanso e Casa Nova. Pelo fato de a riqueza da região ser oriunda da criação de gado e do comércio exportador, e não da propriedade da terra, sustentáculo tido como próprio do coronelismo, a autora procurou identificar os instrumentos utilizados pelos coronéis para se consolidarem no poder.

No que se refere ao exercício de mando do coronelismo, a autora comprovou que em cada região ele assumiu formas diversificadas. Franklin Lins de Albuquerque em Piläo Arado extrapolou os limites territoriais do Município, chegando mesmo a exercer certo mandonismo em Salvador. Soube, inclusive, beneficiar-se de circunstâncias históricas para ampliar e divulgar seu poder no Estado; foi agente histórico na repressão à coluna Prestes. A revolução de 30 foi recebida com resistência por Franklin e Horário de Matos, que logo atenderam ao pedido de Washington Luiz e eshoçaram uma certa mobilização contra os tenentes (MELLO, 1989, p.91).

Em Remanso, a dominação pessoal de Anfilófio Castelo Branco foi diluída entre os membros da família e seus aliados, após a sua morte. Teve a sua base de sustentação 
calcada no seu exército particular [...] por ser chefe político de uma cidade-porto, suas articulações-políticas e comerciais - eram mais abrangentes tanto com outras oligarquias como nas instâncias administrativas do poder (MELLo, 1989, p. 86).

Em Sento Sé, ocorreu um tipo de dominação que não extrapolou os limites do Município. Os coronéis sustentaramse no poder baseados na utilização de instrumentos tradicionais do coronelismo, como a coesão de família, manutenção de clientela, controle sobre cargos públicos e, principalmente, o uso da violência: "Tonhá desenvolveu portanto a sua coerção social mas com base nas relações patriarcais, no 'tête-a-tête' com seus agregados, deixando o uso das armas para situações exteriores" (MELLO, 1989, p. 87).

Em Casa Nova, reduto dos tradicionais Vianas baianos, as possibilidades de mando deram-se em virtude de um poder mais verticalizado com as instâncias administrativas do Estado, portanto um tipo de poder mais estável que os demais. Utilizavam instrumentos de mando bastante diversificados:

usavam a força policial local e abstinham-se de manter jagunços [...]; preferiam fazer as negociações de posse/uso da terra via cartório [...] eram fazendeiros, grandes comerciantes, políticos e até mesmos sacerdotes (MELLo, 1989, p. 88).

Os trabalhos acadêmicos sobre o mandonismo no interior do Estado da Bahia, como foi visto, tratam a República como momento privilegiado para o estudo do mandonismo local e das famílias que, com seus coronéis, comandaram a política de potentados com todas as suas nuanças. O que chama mais a atenção nesses trabalhos é o fato de identificarem o mandonismo e o coronelismo como manifestações idênticas e próprias do 
período republicano. Mesmo com o acompanhamento da trajetória política das famílias locais, esses trabalhos não remontam ao Império e muito menos percebem, nas medidas centralizadoras do Estado Imperial, o grande fator gerador do amesquinhamento do poder local.

O ponto mais importante desses estudos é o de permitir verificar que o mandonismo local no Estado da Bahia não foi uniforme, mas teve especificidades regionais que influenciaram e definiram a forma de mando local, seja na Região Cacaueira, na Chapada Diamantina ou no Vale do São Francisco, regióes selecionadas para a comparação com o mandonismo da Imperial Vila da Vitória (atual município de Vitória da Concuista), região) Centro-Sul do Estado.

Por outro lado, esses estudos provam que o coronelismo, como modelo explicativo da manifestação política do mundo privado, não contempla as especificidades dos "estudos de caso" em nível regional. Partindo-se, seja das teses "localistas", seja das ahordagens "centralistas", há dificuldades em se articular os elementos políticos e econômicos com os elementos propostos por essas duas abordagens.

A idéia de isolamento e de atraso como determinante das manifestações coronelistas não foi comprovada no "estudo de caso" do Vale do São Francisco. Lá, os coronéis, por terem uma base economica ribeirinha e comercial, assumiram um perfil específico que diferenciou os seus mecanismos tradicionais de mando: desenvolveram um sistema de exclusividade na exportação, que submetia a todos os pequenos comerciantes; mantinham na capital casa de estudantes para formação de futuros quadros políticos destinados ao parlamento e abstinham-se de manter jagunços, como os Vianas, que preferiam usar da força policial.

A análise das práticas políticas na Imperial Vila da Vitória (IVO, 1998) mostra que as lutas de família ali existentes 
são conseyüência não só do controle privado das instâncias públicas, mas também resultantes do processo centralizador da organização política e administrativa do Estado.

Partindo da análise de um "estudo de caso" de lutas de família denominado A Tragédia do Tamanduá, a autora analisa o processo de centralização político-administrativa implementado pelo Estado Imperial demonstrando como essas medidas centralizadoras favoreceram a apropriação das instâncias de caráter público pelo poder privado. Por outro lado, demonstra que apesar das restrições da centralização administrativa, os chefes locais pensaram e elaboraram formas de organização e disciplinarização da cidade:

suas atitudes podem ser justificadas pelos atributos assumidos de patrocinadores de coisas e causas, uma vez que o seu prestígio junto à cidade e à população media-se pela capacidade de conceder benefícios e favores (IVO), 1998, p. 183).

Conclui a autora que se em questões políticas assumiam práticas tradicionais e conservadoras, em postos da administraçăo pública, eram os responsáveis pela estruturação física do Município, pela conservação dos logradouros públicos, pela abertura de estradas e caminhos que permitiam o acesso às regiões economicamente importantes para a cidade.

Na Imperial Vila da Vitória, o mandonismo adquiriu características próprias, diferenciando-se dos demais no interior do Estado. Os chefes locais estavam mais preocupados com as questões intestinas do Município e, durante todo o século XIX, demonstraram não privilegiar as questões políticas regionais, tanto que durante esse período, a Vila não produziu nenhum líder cuja atividade política extrapolasse as fronteiras do Município. As disputas pelo controle dos postos de mando locais e a violência 
para com os adversários políticos foram os elementos privilegiados pelos chefes locais.

O acompanhamento das diversidades políticas locais pede uma reinterpretação das sínteses que analisam o coronelismo, muitas vezes visto como sinônimo do mandonismo. A proposição) de o coronelismo ser resultante da decadente força política dos proprietários rurais também vai de encontro com a realidade vivida pelos coronéis, não só do Vale do São Francisco, mas também da Chapada Diamantina. Horácio de Matos, na Chapada Diamantina, e Franklin Lins de Albuquerque no Vale do São Francisco, em determinados momentos históricos, como a Revolução de 30 e a Coluna Prestes, provaram ao poder público a necessidade de serem consultados e, conseqüentemente, de interferirem em questões que a priori seriam próprias do Estado, como poder público organizado.

Em outros momentos, porém, ocorreu a capitulação não só do governo estadual, mas também federal diante do poder político armado dos coronéis. O exemplo mais cabal foi a Revolução Sertaneja liderada por Horácio de Matos.

A idéia de que os mandóes locais são portadores e detentores do atraso - também não corresponde à realidade da Imperial Vila da Vitória. Os chefes locais, como administradores, desenvolveram políticas públicas com alto grau de modernização. Buscaram ordenar o espaço público do Município, visando à modernização e à estruturação física da localidade. Preocupavamse em interligar o Município a outras cidades do Estado e abriam novos caminhos de ligação com o norte de Minas Gerais. Da mesma forma, desenvolviam políticas que visavam à melhoria das vias de acesso a outras regiões do Estado.

O coronelismo, tal como conceituado por Nunes Leal, resultante do enfraquecimento econômico dos proprietários de terras, não pode ser adaptado a realidades locais, mesmo para o 
primeiro período republicano. Como foi visto nos "estudos de caso" da Região Cacaueira, do Vale do São Francisco, da Chapada Diamantina e mesmo do Planalto da Conquista, a atuação política e social desses coronéis em muito se distanciou da característica que fundamenta o compromisso coronelista de Leal, ou seja, a "decadente influência social dos chefes locais" (LEAL, 1975, p. 20).

O mandonismo, inerente ao comportamento político das elites locais, apenas assumiu formas diferentes em determinados momentos históricos. O que é mais importante nesse processo é a compreensão da organização social e política do Estado que se estruturou, permitindo que o poder público fosse apropriado por grupos privados que se utilizaram dele para efetuar os mais variados tipos de desmando e violência em geral. Fosse apropriando-se das instâncias da justiça, fosse por meio do controle do legislativo e executivo locais, o poder local sempre recebeu respaldo das autoridades políticas em nível regional e em nível federal, uma vez que aos mandões locais estava subordinada social e politicamente a população local.

A relação de compromisso recíproco entre os coronéis e o governo, nos primeiros anos republicanos, não existiu em função do poder privado decadente, mas do reconhecimento de que os chefes locais, atuantes politicamente durante todo o Império, ainda eram atores ativos na vida política e pública. O coronelismo nada mais foi do que uma fase do antigo mandonismo, agora adaptado às necessidades de aliança e de compromisso entre o poder público e o poder privado, possibilidade indefinida no Império. Mandonismo e cultura política baseada na violência misturaramse no exercício político discricionário das elites locais. 


\section{Referências Bibliográficas}

BLONDEL, J. As condições da vida política no Estado da Paraíba. Rio de Janciro: Fundação Getúlio Vargas, 1957.

BURSZTYN, M. O poder dos donos: planejamento e clientelismo no nordeste. 2. ed. Petrópolis: Vozes, 1985.

FALCÓN, G. Os coronéis do caccut. Salvador: Ianamá/Centro Editorial e Didático da UFBA, 1995.

FAORO, R. Os domos do poder: formação do patronato político brasileiro. 10. el. São Paulo: Globo, 1996.

IVO, I. P. A Tragédia do Tamanduá: um estudo de caso de poder local e de mandonismo no sertão da Bahia (1840-1895). 1998. Disscrtação (Mestrado em História) - Faculdade de Filosofia e Ciências Humanas, UFMG, Beto Horizonte, 1998.

JANOTTl, M. de L. M. O coromelismo: uma política de compromissos. São Paulo: Brasiliense, 1981. (Coleção Tudoé História).

LEAL, V. N. Commelismo, enxade evoto: o Município e o regime representativo no Brasil. 2. ed. São Paulo: Alfa Ômega, 1975.

. O coronclismo e o coronelismo de cada um. DADOS - Revista de Ciências Sociais, Rio de Janeiro, v. 23, n. 1, p. 11-14, 1980.

MELlo, M. A. G. História política do baixo médio São Francisco. 1989. 139p. Dissertação (Mestrado em Ciências Sociais) - Faculdade de Filosofia c Ciências Humanas, UFBA, Salvador, 1989.

MORAES, W. Jagunços e heróis: a civilização do diamante nas Lavras da Bahia. 2. ed. Salvador: Edições GRD, 1973.

PANG, Eul-Soo. Coronelismo e oligarquias. 1889-1934. A Bahia na Primeira Repuíblica brasileira. Rio de Janeiro: Civilização Brasileira, 1979.

QUEIROZ, M. I. P. de. O coronelismo muma interpretaçũo sociológica. São Paulo: Alfa Ômega, 1976h.

. O mandomismo local na vida política brasileira. São Paulo: Alfa Ômega, 1976a. 
ROSA, D. L. O mandomismo local na Chapada Diamantina. 1973. Dissertação (Mestrado em Ciências Sociais) - Faculdade de Filosofia e Ciências Humanas, UFBA, Salvador, 1973.

VASCONCELOS, J. G. A invenção do coronel: ensaio sobre as raízes do imaginário político brasileiro. Vitória: Gráfica Ita/UFES, 1995.

\section{ABSTRACT:}

The article analyzes the main studies on the patronage showing as the historians they have been defining the incursion of the power deprived in the public institutions. It also discusses the interpretations of that phenomenon inside Bahia, specifically, the researches on the Região Cacauteira, Chapada Diamantina, Baixo-Médio São Francisco and the Planalto da Conyuista.

KEYWORI)S: patronage, power public, power deprived. 